\title{
Chapter 8 \\ On Drenching the Massive, Mature Tourist Destinations in the Sunny and Sandy Social Marketing Innovation
}

\author{
Gonzalo Diáz-Meneses and Ignacio Luri-Rodríguez
}

\section{Introduction}

The application of classic management models for sustainability is not enough to ensure quality of life for local inhabitants in a community with a massive tourism industry. In fact, there remain many unsolved problems in these kinds of resort where the development of tourism not only carries important benefits, but also significant counterproductive consequences. For instance, on the side of benefits, the literature has pointed out the creation of employment and the revitalisation of poor or non-industrialised regions. By contrast, on the side of costs, the literature recognises problems related to traffic congestion and waste management WTO/UNWTO (2004). While it is true that the application of classic management models has been positive in optimising these tourism outcomes, it also seems evident that the results might be improved substantially through the application of the social marketing approach (Mathieson and Wall 1982). On this basis, the first objective to be set out by this book chapter is to describe benefits, as well as costs, associated with massive resorts where the development of tourism might be challenged by making the best use of social marketing. To implement this, European, African, Asian and American examples will be given so that real cases and then actual diagnoses are dealt with.

In addition to this residents' perspective and to consider the visitors angle, it seems logical to think that no resort is able to guarantee quality of life without ensuring what is understood by satisfaction with travel and tourism services. In fact,

\author{
G. Diáz-Meneses $(\bowtie)$ \\ Universidad de Las Palmas de Gran Canaria, Las Palmas, Spain \\ e-mail: gonzalo.diazmeneses@ulpgc.es \\ I. Luri-Rodríguez \\ University of Arizona, Tucson, AZ, USA \\ e-mail: iluri@email.arizona.edu
}


satisfaction with travel and tourism services determines a perception of good experience in the resort and this leads to the feeling of satisfaction with leisure time and life in general (Neal et al. 2007). Consequently, in this book chapter the second objective consisted of posing social marketing as the means of achieving a greater level of visitor's satisfaction with services.

Therefore, in order to accomplish the aim of proposing social marketing as one of the most effective and efficient tools for improving residents, as well as visitors, quality of life, this book chapter is divided into four sections: (1) the theoretical part, where the classic management models for sustainability and the social marketing framework for improving quality of life are contrasted, (2) the social marketing diagnosis for massive tourism industries in order to pose the main problems at the strategic level, (3) the formulation of solutions to overcome the classic starting points and tools, and (4) the conclusions.

\section{Classic Management Models for Sustainability Versus Social Marketing for Improving Quality of Life}

Tourism and QOL: Not only is tourism by itself not enough to improve people's quality of life, but neither is the application of visitor management models able to create well-being, social support and personal development among resort locals. No doubt, there are beneficial impacts associated with tourism and the classic management models are useful for sustainability, but by considering social marketing, more success might be added regarding quality of life. In fact, and from a theoretical point of view, this is so because the topic of quality of life has not been explored sufficiently in the field of tourism (Andereck and Nyaupane 2011), since hardly any social marketing for tourism has even been put into motion, either theoretically or practically speaking (Dinan and Sargeant 2000; Hall 2014) and because the focus of these classic management frameworks are sustainability, there being slight differences between sustainability and quality of life (Andereck et al. 2007).

Despite the undoubted link between tourism and quality of life, little research has been done to reveal how hospitality services influence a traveller's quality of life. Most of this research effort has focused on the perspective of local residents in the host community (Andereck and Nyaupane 2011), but much remains to be done from the visitor's perspective. From the tourist's point of view, consumer satisfaction has been considered to play a significant role for enhancing specific dimensions of the quality of life construct such as longevity, self-esteem and several other aspects of life. Thus, according to Neal et al. (2007), satisfaction with the service aspects of travel phases (pre-trip, en-route, arrival at destination and return services) determines satisfaction with life in general by means of satisfaction with these travel services. Similarly, these authors point out that trip reflections on perceived freedom from control and work, involvement, arousal, mastery and spontaneity influence quality of life through satisfaction with travel experiences. Likewise, satisfaction with leisure experiences at home causes satisfaction with leisure time and life in general. 
The lack of research in this area might be due to the fact that the stress has been put on the community resident structure - the intentions have been prescriptive about what is good for locals and an effort has been made to provide practical management implications to be implemented by the host side. In other words, the bottom line has not been the visitors, as social marketing assumes, but rather the providers, as classic management theory accepts.

In addition to the above reasons, it can be stated that little research has been done along the lines of social marketing for tourism whereby the final aim has been to improve quality of life. To be specific, only a few projects, as well as papers, have been performed under the banner of social marketing in the tourism sector so far. According to Truong and Hall (2013) the lines given limited attention are recreation (Bright 2000), attraction to the desired segment of sustainable tourism (Dinan and Sargeant 2000), change of tourist behaviour regarding gambling, conservation, long-term sociocultural interests and demarketing (Beeton and Benfield 2003), social responsibility in hotels operations to reduce resource use (Shang et al. 2010), poverty alleviation (Truong and Hall 2013) and advertising to dispel negative gender stereotypes (Sirakaya and Sonmez 2000; Chabra et al. 2011). Nevertheless, there are many uncovered lines of research which could consolidate social marketing for tourism. It is imperative that these limitations are overcome since as soon as social marketing is introduced into responsible tourism management, it will create change for improving quality of life, provide better business opportunities and enhance tourist and resident experiences (George and Fry 2010). In Table 8.1, new lines of research are laid out and categorised into six main general fields by considering the notion of impact as systematization criterion.

Table 8.1 Potential lines of research on social marketing for tourism

\begin{tabular}{l|l|l}
\hline General field & Line of research & Example \\
\hline $\begin{array}{l}\text { Tourism physical } \\
\text { impact }\end{array}$ & $\begin{array}{l}\text { Deterioration of landscape and } \\
\text { monuments. Overcrowded cities, } \\
\text { overload of public services and } \\
\text { infrastructure }\end{array}$ & $\begin{array}{l}\text { Degradation of monumental } \\
\text { buildings in Merida, Spain } \\
\text { (Ortiz et al. 2013) }\end{array}$ \\
\hline $\begin{array}{l}\text { Tourism economic } \\
\text { impact }\end{array}$ & $\begin{array}{l}\text { Overpricing, seasonal employment and } \\
\text { unemployment, standardization in offer } \\
\text { of goods and services }\end{array}$ & $\begin{array}{l}\text { Increase of housing prices in } \\
\text { Italian touristic cities (Biagi } \\
\text { et al. 2014) }\end{array}$ \\
\hline $\begin{array}{l}\text { Tourism social } \\
\text { impact }\end{array}$ & $\begin{array}{l}\text { Effect over language and culture. } \\
\text { Satisfaction or dissatisfaction of the } \\
\text { locals with tourism }\end{array}$ & $\begin{array}{l}\text { Tourism impact on the quality } \\
\text { of life of Virginia state } \\
\text { residents (Kim et al. 2013) }\end{array}$ \\
\hline Safety and health & $\begin{array}{l}\text { Alcohol, binge drinking and drugs. Safe } \\
\text { driving. Risk of adventure or sport } \\
\text { tourism. Criminality }\end{array}$ & $\begin{array}{l}\text { Tourism increases criminality } \\
\text { in Spanish touristic cities } \\
\text { (Montolio and Planells-Struse } \\
\text { 2013) }\end{array}$ \\
\hline $\begin{array}{l}\text { Tourist motivators, } \\
\text { barriers and } \\
\text { satisfaction }\end{array}$ & $\begin{array}{l}\text { Demographic profile of tourists. Reasons } \\
\text { to choose a touristic destination. } \\
\text { Perceived image of a destination. } \\
\text { Satisfaction or dissatisfaction, repeat } \\
\text { visitors }\end{array}$ & $\begin{array}{l}\text { Tourists' perception of } \\
\text { Guimarães, Portugal } \\
\text { (Remoaldo et al. 2014) }\end{array}$ \\
\hline
\end{tabular}




\subsection{The Classic Management Models for Sustainability}

Although it goes beyond the scope of this chapter to explain in detail these models, it is relevant to cite one of these classic management models - the one labelled as 'the recreation opportunity spectrum' - whose contribution has been significant in determining a marked threshold of activity beyond which environmental deterioration would be a reality. Another widely known theoretical model is the carrying capacity framework, according to which a diversity of experiences are identified by considering the limits of a particular resort, its reposition and heritage conservation. Similarly, the visitor activity management model tries to conciliate visitor's needs and resources as a means to resolve conflicts. The visitor impact management model's main objectives are measuring and controlling the impact of threats. Furthermore, the limits of acceptable change model addresses how much change is acceptable in a particular area by considering the conditions of visitors. It is also worth mentioning the tourism optimization management model to empower the stake holders, to go back over the viability of the tourism industry and to recognise the importance of heritage conservation (Hall and McArthur 1998).

Most of these classic management techniques consist of regulating, designing spaces by architectonical and engineering means and putting into practice some marketing operations such as market research, promotions and demarketing. Examples of visitor management techniques include regulating access to certain areas by implementing transport and parking measures. Similarly, regulating visitor numbers and group size, types of visitors permitted and visitor behaviour, as well as equipment which could prohibit activities such as off road-driving. Furthermore, the use of entry fees for conservation purposes and modifications to sites by constructing hardened paths to direct visitors. Finally, some marketing actions such as market research to identify reasons for visiting and to understand how to develop tools to modify behaviour and provision of interpretation programmes by providing guided tours or guides to avoid congestion (Hall and McArthur 1998).

As an example of the classic management model's application for sustainability, the Mediterranean archipelago of Baleares is one of the leading tourist destinations in Europe, with over 10 million visitors annually. Forty per cent of the main islands' (Formentera, Ibiza, Menorca and Mallorca) territory is protected, including a UNESCO Biosphere Reserve (Menorca), a World Heritage Site (city of Ibiza), and the Cabrera National Park and over a hundred other protected natural areas.

From 2000 to 2003, the Centre for Tourism Research and Technologies of the Balearic Islands (CITTIB) researched on sustainability and carrying capacity. By 1998, Baleares already had strict regulation that limited development and land use for tourism purposes. However, the results shown by the CITTIB and other studies forced a moratorium in 2002 that prevented further urbanization without prior approval. A new General Tourism Law and Plan to Organize the Tourism Offer (Plan de Ordenacion de la Oferta Turistica) helped protect the land from uncontrolled use. 


\subsection{The Differences Between Management for Sustainability and Social Marketing for Quality of Life}

However, none of these research approaches adopt the precept that the exchange of value is crucial in satisfying consumers' needs; social marketing suggests not only placing emphasis on the exchange of ideas, but also proposes that quality of life be considered. To be specific, social marketing conceives of tourism as a social product with behaviours, rituals, values and symbols related to the participating community's cultural identity, rather than to tangible elements. In other words, culture is central to the exchanges between tourists and residents since it is a system of shared meaning.

Thus, from a tourist's perspective, the product is any activity that could be developed through the visitors' consideration of cultural identity, the environment and other important social issues concerning the resort. From the inhabitant's perspective, the product is any activity developed by natives which takes into account their cultural identity in order to satisfy visitor's needs. Following on from this mixed marketing theory, price in social marketing for tourism would be any effort, sacrifice or perceived time cost for those involved in these kinds of exchanges. For instance, it could stem from any inconvenience related to travel from place of origin to destination, or any bad sensation provoked by saturated physical and affected space, and time. In addition, the place in social marketing for tourism is where cultural exchange take place between inhabitants and visitors. Communication in social marketing for tourism consists of shared meanings and senses which encourage exchanges between locals and visitors.

\section{The Social Marketing Diagnosis for Massive Industries: Posing Problems at the Strategic Level for a Social Marketing Approach}

Considering the review of the classic literature on sustainability for tourism management, the main environmental impacts and problems related to resort areas are the effect of inappropriate hotel development on the traditional landscape, the absence of planning and development restrictions, the overloading of resort infrastructure in periods of peak usage, the segregation of tourists from local residents, the loss of good quality agricultural land to tourist development, traffic congestion, and the fact that local ecosystems may be polluted by sewage and litter from overdemand in the peak season (Mathieson and Wall 1982).

Providing an example of this, the city of Venice (Italy) is one of the better known and most popular tourist destinations in the world. The city's attractiveness could be a reason to worry, however. More than 20 years ago, Canestrelli and Costa (1991) estimated an optimal level for arrivals in the city, and expressed concern that this level had been surpassed by the 80s. The number of tourists has only increased since then. According to the World Monuments Fund (2014), tourist arrivals have risen by $400 \%$ in the last 5 years. 
As a result, the population of Venice is now half that of a decade ago. Inaccessible housing prices, lack of specialized jobs and overloading of public services are creating an exodus that threatens the continuity of one of the most historical cities in Europe.

Some questions might be formulated to measure the major influences on the sociocultural impacts of tourism. According to Mason (2008), these questions should ask who the tourists are, in what type of activities they are engaged, what the scale of tourism is, where tourism is taking place, how able the infrastructure is to deal with demand, what the duration of stay is and what the seasonality of tourism is.

Tourism management requires answers to these questions. As with those in many other popular tourist destinations, authorities in Greece have addressed the topic of seasonality. Since arrivals were not evenly spread throughout the year, how seasonal were the Greek destinations really? Using data from the Greek Tourism Organization and the Greek National Statistical Society, research showed that seasonality was lower in the mainland than in the islands (Donatos and Zairis 1991). While tourism in the small islands was concentrated on the warmer months, Crete was less dependent on these summer visits. Overall, seasonality in Greece is greater than that of competitor countries such as Spain, Italy or Portugal, and could be considered a weakness of the sector (Buhalis 2001).

Problems and questions are often the same but social marketing defines the former in terms of quality of life and the latter in terms of exchanges. Therefore, social marketing for tourism poses a multidimensional approach to problematic issues described by situations such as recycling collaboration and other volunteering responses from visitors, insufficient cultural exchanges between locals and tourists, binge drinking behaviour, saving behaviour related to water and soap by visitors in hotels, overuse of public services, security issues and safety recommendations such as luggage attention and sun protection, safe sexual conduct among young people, respectful reminders for conservation of protected natural areas. Regarding the questions, social marketing wonders who the key exchangers are and suggests that targets for campaigns might be the tourists, the host population, and the tourist industry and government agencies.

Therefore, it is time to bring into focus social marketing as long as this new social science highlights the crucial importance of setting out as an objective the attainment of a better quality of life by encouraging more exchanges between the host community and tourists.

Putting into practice a mixed-marketing approach to assess the massive shortcomings in the tourism product, it might be pointed out that there is frequently an issue regarding a sense of alienation in huge resorts for the host community, in so far as this enormous product offers many elements of foreign identities and too few elements from the local identity, as happens in sun and sand resorts in Spain, Greece, Portugal and Italy for example. Moreover, it might work better on positioning, given that the question being raised at the moment is how to compete with emerging competitors at new resorts in North Africa (such as Marrakesh, Tunisia and Egypt), in Asia (such as Thailand and Malaysia) and in the Caribbean, considering that all of these destinations are committed to improving both infrastructure and quality of 
service. Maybe the answer comes from the fact that the more identity is related to a product, the more difficult it is for competitors to imitate it. However, despite the need to recover or promote a revival of the traditional cultural identity, it is true that there is a cultural generation gap that cannot be bridged by new technologies without transforming this identity into something derivative and inauthentic.

Following the mixed-marketing diagnosis and from a communication perspective, it might be said that, in countries with extensively developed tourist destinations, image is predominant over identity as long as sunny beaches and excellent infrastructure are highlighted instead of reflecting on who the local people are, what they look like and what they do. In this, mass media is responsible, given that powerful adverting and aggressive promotion campaigns are replacing other personal marketing techniques such as direct marketing, public relations and sales forces. Mass media is useful but it emphasizes quantity and non-personal interaction. In addition, it is clear that the positioning advantage of these established sun and sand destinations is under pressure from increasing globalisation and connectivity, which is leading to a non-different positioning since there are more elements from anywhere, anybody and anytime than from particular places, specific characters and special moments. In this industry, English is the predominant language, which would not necessarily be bad were it not for the fact that it is replacing local languages. Why can a language tourism industry not be developed in these resorts by taking up social marketing technologies?

From a place diagnosis, there is a saturated tourist space where the industry seems to look for quantity alone, which is a deceit, given that success should be measured in terms of visitor's satisfaction and not in the increasing number of visitors or tourists. Moreover, it might be stated that in the emerging custom of allinclusive packages, convenience works against freedom and satisfaction since the problem stems not only from forcing choice before the tourist is aware of the destination's culture, environment and other social concerns, but also from inhibiting interaction between tourists and locals. Another place problem stems from the historical reality of the very hasty development and cultural discontinuance that occurred between 1960 and 1990 in many of these massive tourist destinations along with the phenomenon of rapid urbanization, which has caused a gap to widen between rural and urban society, and between tradition and modernity.

From the standpoint of price, this kind of massive tourist destination is facing the dilemma of conciliating good prices and high quality, since the emerging competitors are unbeatable in terms of low cost, given that they are in developing countries where the cost of living is cheaper and tourism packages and services are more affordable. Against these new competitors, the tourism industry is working not only on supplying products and on providing services, but also experiences. However, in many cases these experiences are not related to either social responsibility, environmental issues or cultural local identity. The experiences are designed by making good use of some diversification policies based upon new dimensions, such as congress and health, where sun and sand are often associated to these new lines of product. Thus it attempts to provide added value and consequently higher perceived value. Furthermore, these policies try to follow on from the fact that modern 
marketing highlights the importance of brand rather than price, inviting one to think more in terms of the best or worst rather than in terms of good or bad/expensive or cheap, since value is always positive. Thus, brand equity questions the old considerations and proposes a new framework where knowledge is assimilated into the best operative procedures but is incapable of underlining the importance of value in itself - the value of doing what is right, for example by saving water, recycling and helping others voluntarily. On this basis, the proposed solutions are quite ethically challenging, perhaps because those social causes, humanitarian and environmental concerns are too often avoided.

As a mature tourist destination, the Canary Islands have faced the challenges of a rapidly expanding tourism industry. By 2000, the transformation of the land and problems related to carrying capacity needed to be addressed urgently.

Traditionally, the economy of The Canary Islands had been based on a low-price, sun and sand tourism. However, an overcrowded island loses its appeal to tourists (Santana Jiménez and Hernández 2011). A new model was part of the solution, and more recently the effort has been towards diversifying what's on offer. A tourism consisting of sports, culture or business trips means more added value, higher prices and a sector less dependent on mass- tourism and huge numbers of visitors.

\section{Formulating Solutions to Overcome the Classic Starting Points and Tools}

In order to formulate solutions, it seems pertinent to start with the optimism of the literature on tourism management by recognising the beneficial impacts of tourism. According to Mathieson and Wall (1982) and considering the traditional massive tourism industry in developed countries, tourism was good for the creation of employment and the revitalisation of poor and non-industrialised regions in the 1960s, and for the promotion of the need to conserve areas of outstanding beauty which have aesthetic and cultural value in the 1980s. However, its ability to engender a rebirth of local arts and crafts, a revival of the social and cultural life of the local inhabitants, or the renewal of local architectural traditions, as well as other dimensions of quality of life, might be called into question.

It is clear that social marketing shares the most important salient principles for sustainability, which according to Mason (2008) are the following: sustainable use of resources, a lessening of environmental impacts, reduction of waste and overconsumption, adoption of internal environmental management, provision of support and involvement with green issues, pursuit of responsible marketing, efficient use of resources, the provision of quality tourist products and experiences, and the safeguarding of local cultures and traditions. Nevertheless, social marketing might be more useful than the methods of classic management for sustainability.

Why social marketing? Marketing is the most advanced social science discipline, management technique and philosophy for social change (Kotler et al. 2002). Why this challenge? If the goal is to satisfy clients holistically so that tourism 
development can formulate sustainability and quality of life, it will be necessary to use the local identity with its creative industry and consider social equity, environmental protection and economic sustainability. The role of social marketing should guide the whole process by influencing the acceptance of these social ideas between the stakeholders (Jamrozy 2007). In addition and according to Andreasen (1995), social marketing is more effective and efficient than pedagogy, sociology, persuasion, psychology and a mere management approach to induce desired conduct in society, even against a reluctant target. This is so because social marketing is very effective and efficient in terms of making social change in the intimate personal sphere (thanks to a multifactor - or interdisciplinary - treatment which comes from the above-mentioned social sciences) by segmentation and market research, by putting the tourist as the bottom line, and by putting into motion very sophisticated techniques. In fact, even though it may sound politically incorrect, there are contradictions between sustainability and quality of life; saving water and soap, limiting one's driving speed, paying ecological taxes and recycling might make people feel inconvenienced or put upon since it implies effort, demands overpayment for the same product and might be perceived as coming at the expense of leisure time. Therefore, the objectives of satisfying tourists and locals holistically and filling the slight gap existing between sustainability and quality of life might be achieved by putting into motion social marketing strategies and techniques which could overcome these difficult problems.

Strategically speaking, the first step must be taken in looking at local identity; then the question of what the elements of local identity are must be raised and the dimensions related to culturally-sensitive social conduct highlighted. Therefore, information should be gathered in order to determine and name the symbols of these mature massive sun and sand tourist resorts' identities and uncover their customs and codes of behaviour. Consequently, a scale to measure the cultural identity and social responsibility should be developed which could categorise the following dimensions: history and legends, flora and fauna, gastronomy, festivals and sport, art, monuments and music, as well as local customs and codes of conduct.

The second step to be taken should raise the question of how to involve locals with their cultural identity. The answer should be by implementing techniques and designing messages. Thus, there are not only antecedent (prompts, commitment, blockleader and objectives) and consequent (reward, feedback and negative reinforcement) social marketing techniques, but also affective (emotions), cognitive (information) and conative (experiences) approaches. In any case, social marketing should be taken up not only to produce a cultural revival and enhance environmental sustainability in these mass-tourism areas, but also to encourage creativity, enrich experiences, revitalise existing product and valorise assets so that distinction is achieved and competitive advantage is gained.

The third step to be taken might consist of promoting the visitor adoption process, raising the question of how to connect the local with the tourist. The answer is by destroying barriers (against unawareness, it could be useful to provide information with cultural guides, brochures and digital materials and against indifference, emotional campaigns could be designed whereby emotions would serve to connect 
the tourist with the local inhabitant and both to their social reality) and building facilitators (teaching English to practitioners, as well as offering local languages to visitors). In fact, language is a key feature in any culture; it might be learnt by visitors and language tourism could be developed more extensively. However, the adoption process should be done after performing segmentation studies to connect locals and visitors varying in terms of specificity and objects of cultural, environmental and social interests so that a particular group's experiences might be created (Blamey and Braithwaite 2010). Furthermore, it is not only language that may be shared, but visitors would also be able to learn native cookery, fishing, embroidery, handcrafts, cultivation, among many other such activities, as tourism in these areas became more cultured, knowledge-based and creative. It could be made possible by developing creative spaces, events, relationships and networks in order to enhance visibility, permeability and flexibility. For example, the organisation of workshops, conferences, festivals, interuniversity courses, associations and other potential cocreation opportunities. In addition, a good use of new technologies can be advantageous, for example, by providing the possibility to download an app which would send prompts to make the visitor aware of the surrounding cultural map while wandering around a city, village or particular place. In this way, as far as the visitor drives or walks, information about points of interest in the vicinity such as literary authors' birth places, musical events, historical facts or endemic fauna and flora is updated as they go. The aim is to reach something other than a mere cultural tourism dimension in mass-tourism resorts by consolidating an authentically creative tourism niche in these areas (Richards 2012).

More operationally speaking, social marketers might use social marketing techniques such as the following:

1. The foot-in-the-door technique: This is a method of persuasion that involves getting a person to agree to a large request by first having them agree to a smaller request (Mackenzie-Mohr 2011). For example, trying to encourage a tourist to taste some gastronomical items before they are persuaded to buy it.

2. The face in the door technique: This involves first making an excessive request of the other person which they will most naturally refuse. The trick is to look disappointed but then make a request that is more reasonable. The other person will then be more likely to accept (Mackenzie-Mohr 2011). For example, after having quite a negative emotional reaction to being invited to pay an unaffordable price for a luxury souvenir, they can later be offered a more affordable item such as a CD of folk music.

3. The bait and switch technique (Reilly 1988): This works by adding something additional after getting something perceived as very good value for money. For example, offer tourists something that is very good value (sun \& sand); this should be a real bargain, and an offer they cannot possibly refuse, even if they were not initially considering it. Later, enrich the item with something of less value to them and more profit to you (volunteering).

4. The exchange principle (Evans and Hastings 2008): This is based on the principle that if I do something for someone, they must feel obliged to do something for me. For example, offer tourists free transport to a restaurant and in return they will eat there. 
5. The contrast principle (Thomas 2007): We notice differences between things, but not absolute measures. Offer tourists the following option: going to the disco or going to a folk music festival which includes modern music.

6. The high ball: This takes advantage of the tendency of people to want more. For example, a travel agent takes tourists to hotels and services that they cannot afford. This, however, raises their desires and the package they eventually buy is more expensive than they had originally planned on.

7. Triggering guilt (Donovan and Henley 2010): Guilt as an emotion is the feeling we get when we believe we have committed an offence by compromising an internal value. Remind your civilised visitors of their environmental values, their belief in fair-play and their good-hearted nature to induce a willingness to participate in recycling at the tourist destination.

In addition to this and following the advice of Kotler et al. (2002), some keys to success from social marketing might be proposed:

1. Take advantage of what is known and has been done before. They watch TV on the plane: what is being shown? Show them not only your sun and sand, but also your history and customs.

2. Start with target markets that are ready for action. Targeting cultural habits in the country of origin.

3. Promoting a single specific behavior. What to say? Know about our culture or buy a bottle of wine, a handmade biscuit or a DVD course of folkloric dance music?

4. Incorporating a tangible object to support the desired behavior. Promoting the tourist destination's literature among tourists. What object to select? Probably the best answer is a book of poetry written by a local author.

5. Understand and address perceived benefits and costs. Tell your visitors about the environmental damage provoked by an excessive use of towels and soap and tell them about how they can save some money by reusing.

6. Convenience. Identify the supply channel as many times as you offer a particular handcraft. For example, indicate the shop or workshop where it can be acquired.

7. Using motivating techniques to induce the desired action. If the target shows interest, antecedent techniques are more effective and efficient; if target does not show interest, it is better to apply consequent techniques; if target is reluctant, sanction is the solution. In other words, be not only effective but also efficient.

\section{Conclusions}

Attempting to go further into who is thought to demand control under a pure demarketing approach could be the answer to solving the problems associated with mass tourism (Beeton and Benfield 2002). This book chapter highlights concerns about discouraging tourists in general, or a particular profile of visitor, since it might imply a permanent slowdown crisis for a massive tourism industry. Thus, the 
straightforward classic management approaches are questioned as sustainability might be not competitive in the short term and quality of life might be more so immediately after it is targeted or put in motion as a priority. By contrast, social marketing might bring desired changes to target markets, even in cooperation with original tourist market authorities and companies. In this direction, and although some minor contradictions might be met, social marketing and tourism marketing for sustainable development would be fully compatible. This is so because marketing would be used to change undesired attitudes and behaviour respecting how host members and visitors behave and coexist so that the importance of how members of a community interact with the number and type of visitors and perform leisure activities might be underlined (Batra 2006).

The sun and sand tourism development cycle has reached its mature phase in Europe and this is the reason why a social marketing disruption theory is needed in order to add more value to the impact of massive tourism on not only residents', but also visitors' quality of life (Perdue et al. 1999). Of course the promoted change should be more profitable by means of switching quantities to qualities and by refuting the preconceived idea that the more visitors there are, the more success there will be. Satisfaction is the gate of sustainability and quality of life.

Hopefully, social marketing for creativity might provide intangible competitive advantages in mass tourism resorts by shifting habits and building relational forms of vacation between the visiting and hosting communities. In fact, sun and sand tourism and sustainable tourism should not be considered absolutely opposed if this large-scale tourism is able to induce desired changes in tourists as well as in residents toward a more compatible and integrated framework (Clarke 1997).

The difference between social marketing for tourism in developed countries such as Spain, Greece, Portugal and Italy, and developing countries is substantial since the former aims to optimise quality of life and the latter tries to improve the humanitarian requirements of providing tourism culture service (Alhroot 2012). Nevertheless, the key point is that social marketing for tourism is underdeveloped and it represents an attractive, growing line of research, formulation and implementation.

\section{References}

Alhroot, A. (2012). An evaluation of social marketing in humanitarian tourism requirements by using social networking sites. International Journal of Marketing Studies, 4, 130-137.

Andereck, K., \& Nyaupane, G. (2011). Exploring the nature of tourism and quality of life perceptions among residents. Journal of Travel Research, 50(3), 248-260.

Andereck, K., Valentine, K., Vogt, C., \& Knopf, R. (2007). A cross-cultural analysis of tourism and quality of life perceptions. Journal of Sustainable Tourism, 15(5), 483-502.

Andreasen, A. (1995). Marketing social change. San Francisco: Jossey-Bass.

Batra, A. (2006). Tourism marketing for sustainable development. Assumption University of Bangkok Journal, 26(1), 59-65.

Beeton, S., \& Benfield, R. (2002). Demand control: The case for demarketing as a visitor and environmental management tool. Journal of Sustainable Tourism, 10, 497-513. 
Biagi, B., Brandano, M. G., \& Lambiri, D. (2014). Does tourism affect house prices? Evidence from Italy. Growth and Change. In press.

Blamey, R., \& Braithwaite, V. (2010). A social values segmentation of the potential ecotourism market. Journal of Sustainable Tourism, 5(1), 29-45.

Bright, A. (2000). The role of social marketing in leisure and recreation management. Journal of Leisure Research, 32, 12-17.

Buhalis, D. (2001). Tourism in Greece: Strategic analysis and challenges. Current Issues in Tourism, 4(5), 440-480.

Canestrelli, E., \& Costa, P. (1991). Tourist carrying capacity: A fuzzy approach. Annals of Tourism Research, 18(2), 295-311.

Chabra, D., Andereck, K., Yamanoi, K., \& Plunkett, D. (2011). Gender equity and social marketing: An analysis of tourism advertisements. Journal of Travel and Tourism Marketing, 28, $111-128$.

Clarke, J. (1997). A framework of approaches to sustainable tourism. Journal of Sustainable Tourism, 5(3), 224-233.

Dinan, C., \& Sargeant, A. (2000). Social marketing and sustainable tourism-is there a match? International Journal of Tourism Research, 2, 1-14.

Donatos, G., \& Zairis, P. (1991). Seasonality of foreign tourism in the Greek island of Crete. Annals of Tourism Research, 18(3), 515-519.

Donovan, R., \& Henley, N. (2010). Principles and practice of social marketing (An international perspective). New York: Cambridge University Press.

Evans, D., \& Hastings, G. (2008). Public health branding: Applying marketing for social change. New York: Oxford University Press.

George, R., \& Fry, N. (2010). Creating change in responsible tourism management through social marketing. South Africa Journal of Business Management, 41(1), 11-24.

Hall, M. (2014). Tourism and social marketing. Oxford/New York: Roudledge.

Hall, C. M., \& McArthur, S. (1998). Integrated heritage management. London: Stationery Office. Oxford/NY

Jamrozy, U. (2007). Marketing of tourism: A paradigm shift toward sustainability. International Journal of Culture, Tourism and Hospitality Research, 1(2), 117-130.

Kim, K., Uysal, M., \& Sirgy, M. J. (2013). How does tourism in a community impact the quality of life of community residents? Tourism Management, 36, 527-540.

Kotler, P., Roberto, N., \& Lee, N. (2002). Social marketing: Improving the quality of life. Thousand Oaks: Sage.

Mackenzie-Mohr, D. (2011). Fostering sustainable behaviour: An introduction to community based social marketing. Gabriola Island: New Society Publishers.

Mason, P. (2008). Tourism impacts, planning and management. Oxford: Butterworth Heinemann.

Mathieson, A., \& Wall, G. (1982). Tourism, economic, physical and social impacts. London/New York: Longman Harlow.

Montolio, D., \& Planells-Struse, S. (2013). Does tourism boost criminal activity? Evidence from a top touristic country. Crime and Delinquency. doi:10.1177/0011128713505489.

Neal, J., Usysal, M., \& Sirgy, J. (2007). The effect of tourism services on traveller's quality of life. Journal of Travel Research, 46, 154-163.

Ortiz, P., Antunez, V., Martín, J. M., Ortiz, R., Vázquez, M. A., \& Galán, E. (2013). Approach to environmental risk analysis for the main monuments in a historical city. Journal of Cultural Heritage, 15(4), 432-440.

Perdue, R., Long, P., \& Kang, Y. (1999). Boomtown tourism and resident quality of life: The marketing of gaming to host communities' residents. Journal of Business Research, 44, 165-177.

Reilly, R. (1988). Travel and tourism marketing techniques. The travel management library. Albany: Delmar Publisher.

Remoaldo, P. C., Vareiro, L., Santos, J. F., \& Ribeiro, J. C. (2014). Tourists' perceptions of world heritage destinations: The case of Guimarães (Portugal). Tourism and Hospitality Research, 14(4), 206-218. doi:10.1177/1467358414541457. 